OPEN ACCESS

Edited by:

Hong Fan,

Sichuan University, China

Reviewed by:

Tauqeer Hussain Mallhi,

University of Science,

Malaysia

Amer Hayat Khan,

University of Science,

Malaysia

*Correspondence:

Tong Zhang

zt_doc@ccmu.edu.cn

Hao Wu

whdoc@ccmu.edu.cn

these authors have contributed equally to this work

Specialty section: This article was submitted to

Pharmaceutical Medicine and

Outcomes Research,

a section of the journal

Frontiers in Pharmacology

Received: 28 January 2019

Accepted: 12 August 2019

Published: 12 September 2019

Citation:

Jiang T, Su B, Song T, Zhu Z, Xia $W$,

Dai L, Wang W, Zhang T and Wu H

(2019) Immunological Efficacy

of Tenofovir Disproxil Fumarate-

Containing Regimens in Patients With

HIV-HBV Coinfection: A Systematic

Review and Meta-Analysis.

Front. Pharmacol. 10:1023.

doi: 10.3389/fphar.2019.01023

\section{Immunological Efficacy of Tenofovir Disproxil Fumarate-Containing Regimens in Patients With HIV-HBV Coinfection: A Systematic Review and Meta-Analysis}

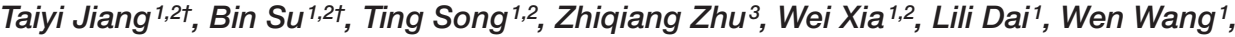 \\ Tong Zhang ${ }^{1,2 *}$ and Hao $\mathrm{Wu}^{1,2 *}$
}

${ }^{1}$ Center for Infectious Diseases, Beijing Youan Hospital, Capital Medical University, Beijing, China, ${ }^{2}$ Beijing Key Laboratory for HIVIAIDS Research, Beijing, China, ${ }^{3}$ Department of Urology, Beijing Youan Hospital, Capital Medical University, Beijing, China

Background: Hepatitis B virus (HBV) coinfection is common in HIV-positive patients. HIV infection modifies the natural course of HBV infection, leading to a faster progression of liver-related morbidity and mortality than is observed in HBV mono-infected patients. This systematic review and meta-analysis evaluates the current clinical evidence regarding the use of oral tenofovir disproxil fumarate (TDF)-based treatments in patients coinfected with HIV and HBV.

Methods: We performed a comprehensive literature search in PubMed and Web of Science. Supplementary searches were conducted in Google Scholar and Clinicaltrials. gov. We conducted a random effects meta-analysis using the event rate (ER) to estimate the incidence of HBV seroconversion. A subgroup meta-analysis was performed to assess the moderate effects of demographic and disease-related variables on HBsAg loss. This review is registered in the PROSPERO database (CRD42018092379).

Results: We included 11 studies in the review. The immunological effects of oral TDFbased Pre-exposure prophylaxis (PrEP) treatment in patients with HIV-HBV coinfection were 0.249 for $\mathrm{HBeAg}$ loss, 0.237 for HBeAg conversion, 0.073 for HBsAg loss, and 0.055 for HBsAg conversion. The factors associated with HBsAg loss were the baseline HBV viral load, participant's location, and a history of exposure to lamivudine/emtricitabine (3TC/FTC) (all $p<0.05$ ). A trend toward a negative relationship between the baseline CD4+ T-cell count and HBsAg loss was observed $(p=0.078)$.

Conclusion: This systematic review and meta-analysis demonstrated that TDFcontaining regimens are effective at stimulating HBeAg loss (24.9\%), HBeAg conversion (23.7\%), HBsAg loss (7.3\%), and HBsAg conversion (5.5\%) in HIV-HBV coinfected patients. The moderator analysis showed that HBV viral load, the location of participants, and prior exposure to 3TC/FTC are factors associated with HBsAg loss. Asian ethnicity, prior exposure to 3TC, and a nondetectable baseline HBV viral load are associated with lower odds of HBsAg loss. Well-designed prospective cohort studies and randomized controlled trials (RCTs) with large sample sizes are required for the investigation of potential 
predictors and biological markers associated with strategies for achieving HBV remission in patients with HIV-HBV coinfection, which is a matter of considerable importance to clinicians and those responsible for health policies.

Keywords: tenofovir disproxil fumarate, drug treatment, outcomes research, meta-analysis, HIV, hepatitis B virus, coinfection

\section{INTRODUCTION}

Approximately 5-25\% of acquired immunodeficiency syndrome (AIDS) patients are coinfected with hepatitis B virus (HBV) (Unaids, 2018). Human immunodeficiency virus (HIV) infection modifies the natural course of $\mathrm{HBV}$ infection, leading to a faster progression of liver-related morbidity and mortality than is observed in $\mathrm{HBV}$ mono-infected individuals, accompanied by a higher prevalence of antiretroviral therapy (ART)-related hepatotoxicity (Avihingsanon et al., 2010). Recent studies have reported that liver disease continues to progress in 10-20\% of individuals on tenofovir-containing $\mathrm{HBV}$-active ART (Coffin et al., 2013; Vinikoor et al., 2017). Tenofovir disproxil fumarate (TDF) is one of the most commonly/widely used nucleotide reverse transcriptase inhibitors (NRTI) for the treatment of HIV and HBV and is recommended by the current HIV treatment guidelines (Aidsinfo, 2018). TDF-containing regimens are particularly favored for the clinical treatment of HIV-HBV coinfection in areas in which resources are limited.

Tenofovir is widely used as a first-line agent for the treatment of chronic HBV infection due to the relatively low levels of drug resistance and high virological efficacy (Nunez et al., 2002; Ristig et al., 2002; Dore et al., 2004; Bihl et al., 2015). A recent study showed that TDF treatment resulted in undetectable levels of HBV in approximately $90 \%$ of patients with HIV-HBV coinfection. This proportion increased rapidly over the first 2 years of treatment and continued to rise slowly thereafter (Price et al., 2013). Moreover, there is currently no confirmed evidence of mutations conferring resistance to TDF in the HBV strains harbored by these patients (Kitrinos et al., 2014).

Interest has recently focused on trying to cure chronic HBV infection. NRTI treatment has been shown to decrease the formation of stable episomal covalently closed circular DNA (cccDNA) and, to a lesser extent, the integration of HBV DNA into the host genome, but HBsAg continues to be produced. Sustained high levels of HBsAg have been associated with a high risk of hepatocellular carcinoma (HCC) in cases of untreated HBV mono-infection (Tseng et al., 2012; Yang et al., 2016). The persistence of cccDNA and HBsAg are the main barriers to curing HBV (Zeisel et al., 2015). HBsAg seroclearance and the development of antibodies against HBsAg can be used to assess HBV function.

Prolonged periods of good response to TDF treatment have been achieved, with HBV DNA remaining undetectable in the serum, but the elimination of cccDNA is the ultimate goal in strategies that aim to cure HBV infection. The concept of a functional cure, defined as the clearance of HBsAg or persistent seroconversion during treatment that may also improve clinical outcomes, has recently been proposed. A loss of the HBsAg biomarker and seroconversion are clearly associated with lower levels of viral activity in the liver and the achievement of HBV remission. The hepatitis B " $\mathrm{e}$ " antigen $(\mathrm{HBeAg})$ can also be used as an alternative biomarker of clinical remission, providing another endpoint indicating a long-term response to NRTIs.

Various studies have shown/reported various degrees of HBsAg loss and/or different seroconversion rates but found differences between coinfections and mono-infections, with higher rates in cases of coinfection. Cumulative HBsAg seroclearance rates of 5\% to $22 \%$ have been reported (Jaroszewicz et al., 2012; Kosi et al., 2012; Maylin et al., 2012; Zoutendijk et al., 2012; Hamers et al., 2013; Matthews et al., 2013; Boyd et al., 2015; Huang and Nunez, 2015; Boyd et al., 2016; Lucifora and Protzer, 2016; Price et al., 2017). A recent meta-analysis focused exclusively on the suppression of $\mathrm{HBV}$ with TDF-containing ART (Price et al., 2013). However, there have been few descriptions of $\mathrm{HBeAg}$ loss or seroconversion to anti$\mathrm{HBe}, \mathrm{HBs} A g$ loss, and the adverse effects of long-term treatment. Therefore, we performed this meta-analysis on data from patients with $\mathrm{HIV} / \mathrm{HBV}$ coinfection to confirm the utility of HBsAg and $\mathrm{HBeAg}$ loss rates as biomarkers and to assess the seroconversion rates and determinants of HBsAg seroclearance during TDF-based treatment for the long-term follow-up of patients coinfected with HIV and HBV. We also considered the factors affecting HBsAg loss.

\section{METHODS}

This systematic review and meta-analysis were performed in accordance with PRISMA guidelines (Moher et al., 2009a; Moher et al., 2009b; Moher et al., 2009c), and the study is registered in the International Prospective Register of Systematic Reviews (PROSPERO, https://www.crd.york.ac.uk/ PROSPERO/): CRD42018092379. The PRISMA checklist is included in Supplementary Table S1.

\section{Search Strategy}

A comprehensive literature search was performed in PubMed and Web of Science. The search terms used were intersections of treatment-related terms (TDF OR tenofovir) and disease terms (HIV OR AIDS OR HBV). Additional searches were also conducted in Google Scholar and ClinicalTrials.gov.

\section{Selection Criteria}

The inclusion criteria were as follows: 1) The study design had to be a randomized controlled trial (RCT) or prospective cohort study; 2) the treatment regimen had to contain TDF with or 
without lamivudine (3TC) and/or emtricitabine (FTC); and 3) there had to be more than 10 participants in the TDF arm to prevent participant bias. We excluded 1) case reports; 2) review articles or theoretical articles; and 3) $\mathrm{PhD}$ theses, dissertations, and book chapters. Thus, to be more specific, 1) the participants were HIV-HBV coinfected patients at the screening stage of each study; 2) the eligible intervention contained TDF with or without 3TC and/or FTC, which are commonly used treatment combinations in most countries and regions; 3 ) some studies included in our meta-analysis were single-arm observational cohorts, while some studies compared the effectiveness between different treatment regimens; if the study arms used the medication combinations of interest, we included all arms; 4) because we aimed to investigate the immunological effects of targeted treatments, the outcomes of interest were $\mathrm{HBV}$-related physiological processes during treatment. HBeAg and HBsAg are two key biomarkers for these processes; thus, we shifted our attention to the micro-level to detect the potential treatment efficacy. Two researchers independently performed the initial search, selecting studies on the basis of their titles and abstracts. The studies retained were then independently screened by a full-text assessment performed by the same researchers (TJ and TS). Disagreements between reviewers about study eligibility were resolved by discussion with BS. The procedure used for this study selection and the numbers of studies included and excluded are shown in Figure 1.

\section{Data Extraction and Code}

The data of interest were independently extracted by two researchers (TJ and WX). The outcomes of interest were HBsAg and $\mathrm{HBeAg}$ seroconversion. The additional information extracted from articles included article author(s), year of publication, study location, sample size, study design, treatment regimen, and disease-related variables.

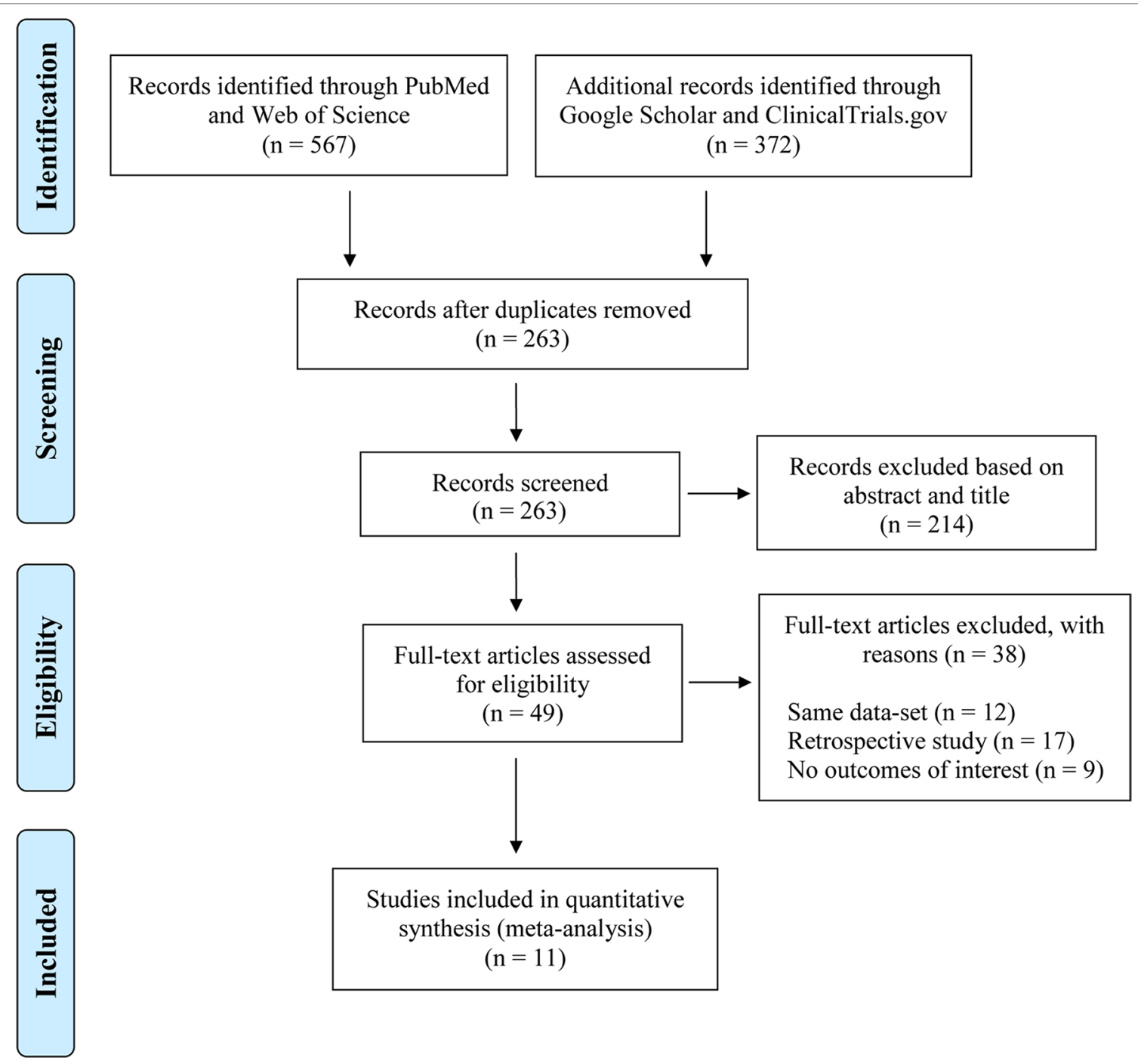

FIGURE 1 | Flow chart of included studies. 


\section{DATA ANALYSIS}

We performed a quantitative analysis with Comprehensive MetaAnalysis (CMA) Version 2.0 (Biostat, Englewood, NJ, U.S.). We first calculated the combined event rate (ER) from the number of events and the sample size of the TDF-based treatment arm. A random effects meta-analysis was conducted with the ER to estimate $\mathrm{HBeAg}$ loss, $\mathrm{HBeAg}$ conversion, $\mathrm{HBsAg}$ loss, and HBsAg conversion. Thus, the ER in different figures denotes the pooled ERs for $\mathrm{HBeAg}$ loss, $\mathrm{HBeAg}$ conversion, $\mathrm{HBsAg}$ loss, and HBsAg conversion. The variation in effect size across studies was assessed by calculating the homogeneity statistic Q. The $I^{2}$ statistic was also used to estimate the proportion of heterogeneity in the observed variance (Higgins and Thompson, 2002). A subgroup meta-analysis was performed to assess the moderate effects of demographic and disease-related variables on HBsAg loss.

\section{Study Quality and Publication Bias}

The Newcastle-Ottawa Scale (NOS) was adopted to evaluate the study quality of the nonrandomized studies, and the Physiotherapy Evidence Database (PEDro) scale was used to assess the study quality of RCTs (http://www.ohri.ca/programs/ clinical_epidemiology/oxford.asp) (Moseley et al., 2002). The individual study quality for the included studies is shown in Supplementary Table S2.

Egger's intercept test and fail-safe $\mathrm{N}$ were used to assess publication bias across studies (Rosenthal, 1979; Stuck et al., 1998). The trim-and-fill method was used if significant publication bias was detected by Egger's test (Rosenthal, 1979). A subgroup meta-analysis was performed to assess the moderate effects of demographic and disease-related variables on HBsAg loss.

\section{RESULTS}

\section{Characteristics of the Studies Included}

We identified 11 studies eligible for this review, with sample sizes ranging from 10 to 100 (Dore et al., 2004; Stephan et al., 2005; Matthews et al., 2008; Nuesch et al., 2008; Avihingsanon et al., 2010; Hamers et al., 2013; Matthews et al., 2013; Huang and Nunez, 2015; Boyd et al., 2016; Li et al., 2016; Wu et al., 2016). We included three RCTs and eight prospective cohort studies. All participants were adults over the age of 18 years. The most commonly/frequently used ART regimen was TDF with 3TC or FTC. Five studies examined TDF-naive patients, whereas the other six studies examined treatment in 3TC-experienced patients. These studies reported various outcomes, including seroconversion for HBsAg and HBeAg. Detailed information about the studies included is provided in Table $\mathbf{1}$.

\section{HBeAg Loss}

The effect of TDF-containing treatment on HBeAg loss was reported for nine arms in eight studies. Therefore, it was possible to analyze the ER of each study. Egger's intercept test showed no significant publication bias (Kendall's tau $=-1.556, p=0.264$ ), and the classic fail-safe $\mathrm{N}$ test showed that 63 missing studies would be required to obtain a non-significant result $(p>0.05)$. The combined ER for HBeAg loss was 0.249 (95\% CI: 0.155-0.376, $p<0.001$, Figure 2). There was significant heterogeneity across studies $\left[\mathrm{Q}(8)=18.092, p=0.021, \mathrm{I}^{2}=55.782\right]$.

\section{HBeAg Conversion}

The effect of TDF-containing treatment on HBeAg conversion was reported for nine arms in eight studies, making it possible

TABLE 1 | Characteristics of the included studies.

\begin{tabular}{|c|c|c|c|c|c|c|c|c|c|}
\hline Names & Location & $\begin{array}{l}\text { Year of } \\
\text { Publication }\end{array}$ & $\mathbf{N}$ & $\begin{array}{l}\text { Study } \\
\text { Design }\end{array}$ & $\begin{array}{l}\text { Treatment } \\
\text { Regimen }\end{array}$ & $\begin{array}{l}\text { Baseline } \\
\text { HBV RNA } \\
\text { (log10 c/ml) }\end{array}$ & $\begin{array}{l}\text { Baseline } \\
\text { HIV RNA } \\
(\log 10 \mathrm{c} / \mathrm{ml})\end{array}$ & $\begin{array}{l}\text { CD4 } \\
\text { (cells/ } \mu \mathrm{l})\end{array}$ & $\begin{array}{l}\text { Duration } \\
\text { (weeks) }\end{array}$ \\
\hline Matthews & Thailand & 2008 & 23 & $\mathrm{RCT}$ & $\begin{array}{l}\text { TDF+3TC } \\
\text { TDF }^{@}\end{array}$ & $\begin{array}{l}8.4 \\
8.6\end{array}$ & $\begin{array}{l}4.7 \\
5\end{array}$ & $\begin{array}{l}39 \\
25\end{array}$ & $\begin{array}{l}48 \\
48\end{array}$ \\
\hline $\mathrm{Li}$ & China & 2016 & 91 & Prospective & TDF+3TC \# & 3.49 & 4.7 & 229 & 48 \\
\hline Stephan & German & 2005 & 31 & Prospective & TDF-based\# & & & & 48 \\
\hline Matthews & Thailand & 2013 & 47 & Prospective & $\begin{array}{l}\text { 3TC+TDF or } \\
\text { TDF/FTC }\end{array}$ & 8.56 & 4.71 & 48 & 108 \\
\hline Dore & $\begin{array}{l}\text { Western Europe, } \\
\text { North America, } \\
\text { Australia }\end{array}$ & 2004 & 10 & Prospective & TDF-based\# & 8.6 & 3.4 & 497 & 48 \\
\hline Wu & China & 2016 & 100 & Prospective & TDF+3TC @\# & 6.9 & 4.2 & 186.5 & 48 \\
\hline Huang & Taiwan & 2016 & 89 & Prospective & TDF-based" & 6 & 4.7 & 361 & 144 \\
\hline Nuesch & Thailand & 2008 & 16 & RCT & TDF/FTC ${ }^{@}$ & 4.6 & 2.7 & 363 & 69 \\
\hline Avihingsanon & $\begin{array}{l}\text { Netherlands } \\
\text { Australia } \\
\text { Thailand }\end{array}$ & 2010 & 10 & RCT & TDF/FTC ${ }^{@}$ & 8.54 & 4.9 & 69 & 48 \\
\hline Boyd & $\begin{array}{l}\text { Côte d'Ivoire } \\
\text { South Africa }\end{array}$ & 2016 & 85 & Prospective & TDF/FTC ${ }^{@}$ & & & & 142 \\
\hline Hamers & $\begin{array}{l}\text { South Africa, } \\
\text { Zambia }\end{array}$ & 2013 & 93 & Prospective & TDF-based ${ }^{@ \#}$ & 5.18 & 4.91 & & 48 \\
\hline
\end{tabular}

${ }^{\circledR T D F-n a i v e ; ~ \# 3 T C-e x p e r i e n c e . ~}$ 


\begin{tabular}{|c|c|c|c|c|c|}
\hline \multicolumn{2}{|c|}{ Study name } & \multicolumn{4}{|c|}{ Statistics for each study } \\
\hline & $\begin{array}{c}\text { Event } \\
\text { rate }\end{array}$ & $\begin{array}{c}\text { Lower } \\
\text { limit }\end{array}$ & $\begin{array}{l}\text { Upper } \\
\text { limit }\end{array}$ & Z-Value & $p$-Value \\
\hline \multicolumn{2}{|c|}{ Matthews-10.429 } & 0.144 & 0.770 & -0.377 & 0.706 \\
\hline \multicolumn{2}{|c|}{ Matthews-20.167 } & 0.023 & 0.631 & -1.469 & 0.142 \\
\hline $\mathrm{Li}$ & 0.429 & 0.240 & 0.640 & -0.652 & 0.514 \\
\hline Stephan & 0.105 & 0.026 & 0.337 & -2.863 & 0.004 \\
\hline Matthews & 0.481 & 0.304 & 0.664 & -0.192 & 0.847 \\
\hline Dore & 0.200 & 0.050 & 0.541 & -1.754 & 0.080 \\
\hline Wu & 0.220 & 0.126 & 0.355 & -3.707 & 0.000 \\
\hline Huang & 0.088 & 0.029 & 0.240 & -3.862 & 0.000 \\
\hline \multirow[t]{2}{*}{ Nuesch } & 0.143 & 0.020 & 0.581 & -1.659 & 0.097 \\
\hline & 0.249 & 0.155 & 0.376 & -3.633 & 0.000 \\
\hline
\end{tabular}

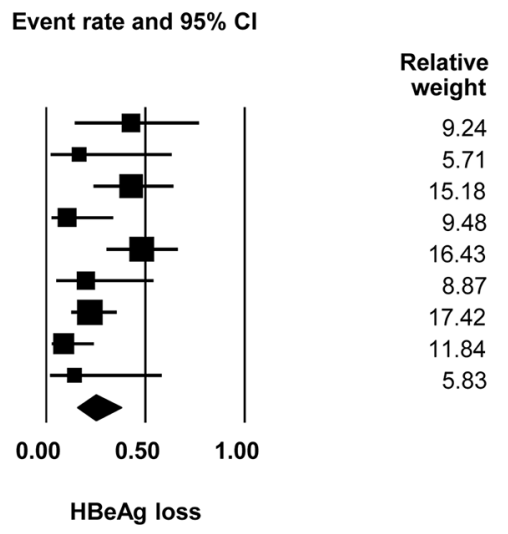

FIGURE 2 | Forest plot for HBeAg loss rates during TDF-containing treatment.

to analyze the ER of each of these studies. Egger's intercept test showed that there was no significant publication bias (Kendall's tau $=-1.461, p=0.127)$, and the classic fail-safe $\mathrm{N}$ tests showed that 70 missing studies would be required to obtain a non-significant result $(p>0.05)$. The combined ER for HBeAg loss was 0.237 (95\% CI: $0.145-0.362, p<0.001$, Figure 3). There was significant heterogeneity across studies $\left[\mathrm{Q}(8)=17.405, p=0.026, \mathrm{I}^{2}=54.036\right]$.

\section{HBsAg Loss}

The effect of TDF-containing treatment on HBsAg loss was reported for 10 arms in nine studies, so it was possible to analyze the ER of each study. Egger's intercept test showed that there was no significant publication bias (Kendall's tau $=-0.667, p=0.617$ ), and the classic fail-safe $\mathrm{N}$ test showed that 356 missing studies would be required to obtain a non-significant result $(p>0.05)$. The combined ER for HBsAg loss was 0.073 (95\% CI: 0.044-0.119, $p<0.001$, Figure 4). There was no significant heterogeneity across studies $\left[\mathrm{Q}(9)=14.433, p=0.108, \mathrm{I}^{2}=37.641\right]$.
Three studies with four arms were performed in Asia, and the other six studies were performed elsewhere. Stratification based on the location showed that location had a significant effect on the TDF-containing regimens $[\mathrm{Q}(1)=5.233, p=0.022$, Asia vs. other countries: 0.037 (95\% CI: $0.018-0.077)$ vs. 0.099 (95\% CI: 0.058-0.164)].

Two studies included patients with $\mathrm{CD} 4^{+} \mathrm{T}$-cell counts of at least 200 cells $/ \mu \mathrm{l}$, whereas five studies included patients with fewer than 200 cells/ $\mu$ l. Stratification based on the baseline CD $4^{+}$ T-cell counts revealed an effect of marginal significance on the efficacy of TDF-containing regimens $[\mathrm{Q}(1)=3.095, p=0.078$, 200 or more cells/ $\mu \mathrm{l}$ vs. fewer than 200 cells/ $\mu \mathrm{l}$ : 0.039 95\% CI: $0.015-0.098$ vs. $0.09495 \%$ CI (0.026-0.218)].

In five studies with six arms, 3TC was used before TDF, whereas in three studies, TDF was used in patients not previously exposed to 3TC. Prior exposure to 3TC significantly affected the efficacy of TDF-containing regimens $[\mathrm{Q}(1)=4.204$, $p=0.04$, yes vs. no: $0.04195 \%$ CI (0.017-0.099) vs. $0.10995 \% \mathrm{CI}$ $(0.068-0.169)]$.

\begin{tabular}{|c|c|c|c|c|c|}
\hline \multirow[t]{2}{*}{ Study nam } & \multicolumn{5}{|c|}{ Statistics for each study } \\
\hline & $\begin{array}{c}\text { Event } \\
\text { rate }\end{array}$ & $\begin{array}{c}\text { Lower } \\
\text { limit }\end{array}$ & $\begin{array}{c}\text { Upper } \\
\text { limit }\end{array}$ & Z-Value & $p$-Value \\
\hline Matthews- & 10.429 & 0.144 & 0.770 & -0.377 & 0.706 \\
\hline Matthews- & 20.167 & 0.023 & 0.631 & -1.469 & 0.142 \\
\hline $\mathrm{Li}$ & 0.429 & 0.240 & 0.640 & -0.652 & 0.514 \\
\hline Stephan & 0.053 & 0.007 & 0.294 & -2.813 & 0.005 \\
\hline Matthews & 0.444 & 0.272 & 0.631 & -0.576 & 0.565 \\
\hline Dore & 0.100 & 0.014 & 0.467 & -2.084 & 0.037 \\
\hline Wu & 0.180 & 0.096 & 0.311 & -4.119 & 0.000 \\
\hline Huang & 0.147 & 0.063 & 0.308 & -3.630 & 0.000 \\
\hline \multirow[t]{2}{*}{ Nuesch } & 0.143 & 0.020 & 0.581 & -1.659 & 0.097 \\
\hline & 0.237 & 0.145 & 0.362 & -3.805 & 0.000 \\
\hline
\end{tabular}

Event rate and $95 \% \mathrm{CI}$

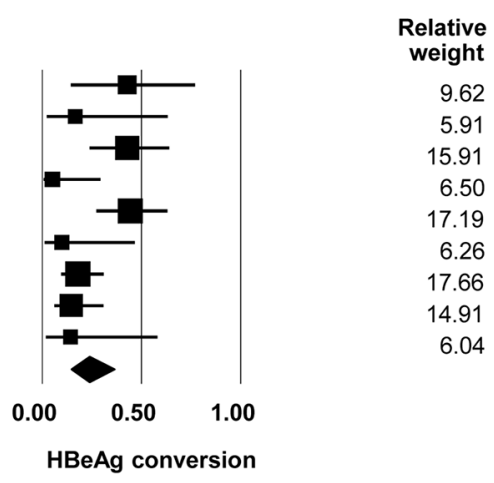

FIGURE 3 | Forest plot for HBeAg conversion rates during TDF-containing treatment. 


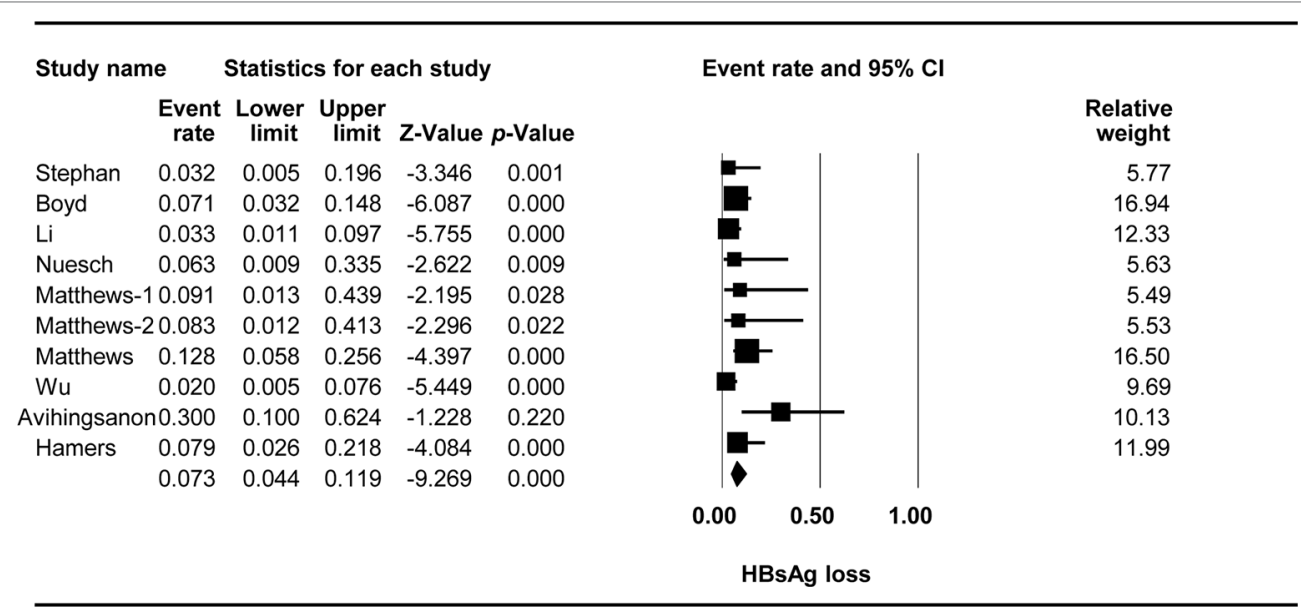

FIGURE 4 | Forest plot for HBsAg loss rates during TDF-containing treatment.

Six studies reported detectable $\mathrm{HBV}$ at the baseline, whereas three studies with four arms reported undetectable $\mathrm{HBV}$ at the baseline. The baseline HBV viral load significantly affected the efficacy of TDF-containing regimens $[\mathrm{Q}(1)=$ $7.938, p=0.005$, yes vs. no: $0.14795 \%$ CI $(0.083-0.247)$ vs. 0.05 95\% CI (0.031-0.08)].

\section{HBsAg Conversion}

The effect of TDF-containing treatments on HBsAg loss was reported in nine studies with 10 arms, making it possible to analyze the ER of each of these studies. Egger's intercept test showed that there was no significant publication bias (Kendall's tau $=-0.753, p=0.886$ ), and the classic fail-safe $\mathrm{N}$ test showed that 56 missing studies would be required to obtain a nonsignificant result $(p>0.05)$. The combined ER for HBeAg loss was 0.055 (95\% CI: $0.02-0.142, p<0.001$, Figure 5). There was no significant heterogeneity across studies $[\mathrm{Q}(3)=5.81$, $\left.p=0.121, \mathrm{I}^{2}=48.365\right]$.

\section{DISCUSSION}

This systematic review and meta-analysis provides pooled estimates of the serological outcomes of TDF-containing regimens in patients with HIV-HBV coinfection. The overall estimates are useful for targeted treatments in key populations.

We found that almost a quarter of the participants experienced serological changes in HBeAg. However, these results should be interpreted with caution due to a relatively high degree of heterogeneity among the studies included. The rates of $\mathrm{HBeAg}$ loss ranged from $8.8 \%$ to $48 \%$, and the rates of $\mathrm{HBeAg}$ seroconversion ranged from $10 \%$ to $44 \%$. The causes of this heterogeneity should be identified, as long-term treatment resulted in higher rates of $\mathrm{HBeAg}$ loss and seroconversion. The combination of TDF $+3 \mathrm{TC} / \mathrm{FTC}$ seemed to be more effective in patients with documented 3TC resistance (Luo et al., 2018). Differences in immune restoration after ART initiation were observed, with various rates of $\mathrm{HBeAg}$ seroclearance, as a sudden increase in $\mathrm{CD}^{+} \mathrm{T}$-cell counts may promote a rapid immune response (Miailhes et al., 2007).

\begin{tabular}{|c|c|c|c|c|c|}
\hline \multirow[t]{2}{*}{ Study nam } & \multicolumn{5}{|c|}{ Statistics for each study } \\
\hline & $\begin{array}{c}\text { Event } \\
\text { rate }\end{array}$ & $\begin{array}{l}\text { Lower } \\
\text { limit }\end{array}$ & $\begin{array}{c}\text { Upper } \\
\text { limit }\end{array}$ & Z-Value & $p$-Value \\
\hline $\mathrm{Li}$ & 0.022 & 0.006 & 0.084 & -5.308 & 0.000 \\
\hline Matthews & 0.064 & 0.021 & 0.180 & -4.501 & 0.000 \\
\hline Avihingsanon & 0.200 & 0.050 & 0.541 & -1.754 & 0.080 \\
\hline \multirow[t]{2}{*}{ Hamers } & 0.026 & 0.004 & 0.165 & -3.563 & 0.000 \\
\hline & 0.055 & 0.020 & 0.142 & -5.366 & 0.000 \\
\hline
\end{tabular}

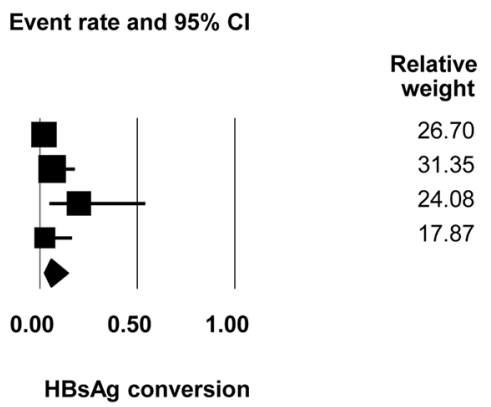

FIGURE 5 | Forest plot for HBsAg conversion rates during TDF-containing treatment. 
HBsAg loss was observed in $7.3 \%$ of the coinfected patients, and the HBV curve was recorded in $5.5 \%$ of participants, which was consistent with the results of previous observational studies (Martin-Carbonero et al., 2011; Van Griensven et al., 2014). Understanding the predictors of HBsAg loss is an important research priority in the search for novel strategies for achieving HBV remission, and individuals with HIV$\mathrm{HBV}$ coinfection may constitute a unique group for studying such associations.

Minor immunosuppression appeared to influence the baseline $\mathrm{HBsAg}$ and $\mathrm{HBeAg}$ levels, with a negative impact on the decrease in HBsAg and HBeAg levels. In our review, we found that patients with $\mathrm{CD} 4^{+} \mathrm{T}$-cell counts below 200 cells/ $\mu$ and higher HBV DNA levels at the baseline were more likely to display HBsAg loss than were their counterparts. This might reflect robust immune reconstitution and the acquisition of enhanced pathogen-specific innate or adaptive immune responses following treatment with TDF-containing regimens (Hsu et al., 2012; Boyd et al., 2015). However, a previous study showed that patients with $\mathrm{CD} 4^{+} \mathrm{T}$-cell counts below 300 cells/ $\mu$ l during TDF-containing treatment, a level considered to constitute mild immunosuppression, cannot achieve a strong enough immune response to clear infected hepatocytes (De Vries-Sluijs et al., 2010).

Higher levels of HBV DNA and exposure to 3TC are associated with longer times before the achievement of undetectable levels of HBV DNA while receiving TDF (Childs et al., 2013), and a longer time to the occurrence of an immunological response represented by HBsAg loss. Therefore, studies in real-world settings are required to determine the effects on HBsAg and HBeAg seroclearance in patients with prior $3 \mathrm{TC}$ treatment and patients receiving TDF-based ART as the initial treatment.

We detected differences between Asia and other parts of the world, with HIV-induced immunosuppression associated with different degrees of HBsAg loss in patients with HBVHIV coinfection. Many studies have shown that genotype A is the most prevalent $\mathrm{HBV}$ genotype in non-Asian populations, which display higher levels of $\mathrm{HBeAg}$ and $\mathrm{HBsAg}$ during natural infections and following IFN treatment (Erhardt et al., 2005; Flink et al., 2006; Thio and Locarnini, 2007). The HBV genotype distribution is different in Asia and other regions; thus, the subtypes of $\mathrm{HBV}$ and their virological responses require further investigation.

Although the safety of TDF-containing regimens was not our primary outcome of interest in this meta-analysis, substantial attention should be paid by health providers and policymakers to monitoring potential side effects in people living with HIV-HBV coinfection. An elevated incidence of renal and liver dysfunction was detected among HIV-HBV coinfected participants on long-term TDF treatment in recent studies (Peters et al., 2006; Tan et al., 2009). Although few studies have reported potential side effects on bone mineral density among HIV-HBV coinfected patents, a recent systematic review and meta-analysis among people mono-infected with HBV or HIV have reported reduced bone density and an elevated incidence of bone fracture due to long-term use of TDF-containing treatments (Buti et al., 2018; Goh et al., 2018). Thus, considering the high availability and low cost of TDF-based treatment in middle- or low-income settings among HIV-HBV coinfected participants, it is better to closely monitor and promptly treat these side effects. In addition, in developed or high-income countries, clinicians may choose treatment regimens with fewer side effects, such as tenofovir alafenamide (TAF)-based treatment regimens.

This review has several limitations. First, the results should be interpreted with caution due to the limited number of comparisons included, potentially restricting the external validity of the conclusions in other settings and decreasing the statistical power to detect potentially significant results. Second, the relatively high level of heterogeneity may have decreased the representativeness of some outcomes (i.e., HBeAg loss and conversion). Third, only a few studies reported adverse events related to kidney and liver function, and this may limit attempts to quantitatively assess the safety of TDF-containing regimens in patients with HIV-HBV coinfection.

\section{CONCLUSION}

This systematic review and meta-analysis demonstrated that TDF-containing regimens are effective at stimulating $\mathrm{HBeAg}$ loss (24.9\%), HBeAg conversion (23.7\%), HBsAg loss (7.3\%), and HBsAg conversion (5.5\%) in HIV-HBV coinfected patients. The moderator analysis showed that Asian ethnicity, prior exposure to 3TC, and nondetectable baseline HBV viral load are associated with lower odds of HBsAg loss. However, we should cautiously interpret the results regarding $\mathrm{HBeAg}$ loss and $\mathrm{HBeAg}$ conversion due to significant heterogeneity across all study arms. Well-designed prospective cohort studies and RCTs with large sample sizes are required for the investigation of potential predictors and biological markers associated with strategies for achieving HBV remission in patients with HIV-HBV coinfection, which is a matter of considerable importance to clinicians and those responsible for health policies.

\section{AUTHOR CONTRIBUTIONS}

TJ, BS, and HW conceived and designed the protocol and study. TJ, ZZ, WX, TZ, and HW identified studies to be screened. TJ, BS, TS, LD, WW, and TZ identified studies for eligibility, extracted data, and assessed the methodological quality of included studies. TJ and BS wrote the manuscript. All authors read and approved the final manuscript.

\section{FUNDING}

This work was supported by the National 13th FiveYear Grand Program on Key Infectious Disease Control 
(2018ZX10301-407-005 and 2018ZX10302103-001-003 to TJ, 2017ZX10202102-005-003 to BS, and 2017ZX10202101-004001 to TZ), the National Natural Science Foundation of China (NSFC, 81772165 to BS and 81571973 to HW), the NSFC-NIH Biomedical collaborative research program (81761128001 to HW), the Beijing Municipal of Science and Technology Major Project (D161100000416003 to HW), the Funding for Chinese overseas talents returning to China in 2016-Beijing Municipal Human Resources and Social Security Bureau (to BS), and the Beijing Key Laboratory for HIV/AIDS Research

\section{REFERENCES}

Aidsinfo. Panel on antiretroviral guidelines for adults and adolescents. Guidelines for the use of antiretroviral agents in adults and adolescents living with HIV. https://aidsinfo.nih.gov/contentfiles/lvguidelines/adultandadolescentgl.pdf.

Avihingsanon, A., Lewin, S. R., Kerr, S., Chang, J. J., Piyawat, K., Napissanant, N., et al. (2010). Efficacy of tenofovir disoproxil fumarate/emtricitabine compared with emtricitabine alone in antiretroviral-naive HIV-HBV coinfection in Thailand. Antiviral Therapy 15, 917-922. doi: 10.3851/IMP1645

Bihl, F., Martinetti, G., Wandeler, G., Weber, R., Ledergeber, B., Calmy, A., et al. (2015). HBV genotypes and response to tenofovir disoproxil fumarate in HIV/HBV-coinfected persons. BMC Gastroenterol. 15, 79. doi: 10.1186/ s12876-015-0308-0

Boyd, A., Gozlan, J., Miailhes, P., Lascoux-Combe, C., Cam, M. S., Rougier, H., et al. (2015). Rates and determinants of hepatitis B 'e' antigen and hepatitis B surface antigen seroclearance during long-term follow-up of patients coinfected with HIV and hepatitis B virus. AIDS 29, 1963-1973. doi: 10.1097/ QAD.0000000000000795

Boyd, A., Maylin, S., Moh, R., Mahjoub, N., Gabillard, D., Eholie, S. P., et al. (2016). Hepatitis B surface antigen quantification as a predictor of seroclearance during treatment in HIV-hepatitis B virus coinfected patients from SubSaharan Africa. J. Gastroenterol. Hepatol. 31, 634-644. doi: 10.1111/jgh.13156

Buti, M., Riveiro-Barciela, M., and Esteban, R. (2018). Long-term safety and efficacy of nucleo(t)side analogue therapy in hepatitis B. Liver Int. 38 Suppl 1, 84-89. doi: 10.1111/liv.13641

Childs, K., Joshi, D., Byrne, R., Bruce, M., Carey, I., Agarwal, K., et al. (2013). Tenofovir-based combination therapy for HIV/HBV co-infection: factors associated with a partial HBV virological response in patients with undetectable HIV viraemia. AIDS 27, 1443-1448. doi: 10.1097/QAD.0b013e32836011c2

Coffin, C. S., Osiowy, C., Myers, R. P., and Gill, M. J. (2013). Virology and clinical sequelae of long-term antiviral therapy in a North American cohort of hepatitis B virus (HBV)/human immunodeficiency virus type 1 (HIV-1) co-infected patients. J. Clin. Virol. 57, 103-108. doi: 10.1016/j.jcv.2013.02.004

De Vries-Sluijs, T. E., Reijnders, J. G., Hansen, B. E., Zaaijer, H. L., Prins, J. M., Pas, S. D., et al. (2010). Long-term therapy with tenofovir is effective for patients co-infected with human immunodeficiency virus and hepatitis B virus. Gastroenterology 139, 1934-1941. doi: 10.1053/j.gastro.2010.08.045

Dore, G. J., Cooper, D. A., Pozniak, A. L., Dejesus, E., Zhong, L., Miller, M. D., et al. (2004). Efficacy of tenofovir disoproxil fumarate in antiretroviral therapy-naive and -experienced patients coinfected with HIV-1 and hepatitis B virus. J. Infect. Dis. 189, 1185-1192. doi: 10.1086/380398

Erhardt, A., Blondin, D., Hauck, K., Sagir, A., Kohnle, T., Heintges, T., et al. (2005). Response to interferon alfa is hepatitis B virus genotype dependent: genotype A is more sensitive to interferon than genotype D. Gut 54, 1009-1013. doi: 10.1136/gut.2004.060327

Flink, H. J., Van Zonneveld, M., Hansen, B. E., De Man, R. A., Schalm, S. W., and Janssen, H. L. (2006). Treatment with Peg-interferon alpha-2b for HBeAgpositive chronic hepatitis B: HBsAg loss is associated with HBV genotype. Am J. Gastroenterol. 101, 297-303. doi: 10.1111/j.1572-0241.2006.00418.x

Goh, S. S. L., Lai, P. S. M., Tan, A. T. B., and Ponnampalavanar, S. (2018). Reduced bone mineral density in human immunodeficiency virus-infected individuals: a meta-analysis of its prevalence and risk factors: supplementary presentation. Osteoporos. Int. 29, 1683. doi: 10.1007/s00198-018-4379-y
(BZ0089). The funders had no role in the study design, data collection and analysis, decision to publish, or preparation of the manuscript.

\section{SUPPLEMENTARY MATERIAL}

The Supplementary Material for this article can be found online at: https://www.frontiersin.org/articles/10.3389/fphar.2019.01023/ full\#supplementary-material.

Hamers, R. L., Zaaijer, H. L., Wallis, C. L., Siwale, M., Ive, P., Botes, M. E., et al. (2013). HIV-HBV coinfection in Southern Africa and the effect of lamivudineversus tenofovir-containing cART on HBV outcomes. J. Acquir. Immune Defic. Syndr. 64, 174-182. doi: 10.1097/QAI.0b013e3182a60f7d

Higgins, J. P., and Thompson, S. G. (2002). Quantifying heterogeneity in a metaanalysis. Stat. Med. 21, 1539-1558. doi: 10.1002/sim.1186

Hsu, D. C., Zaunders, J. J., Plit, M., Leeman, C., Ip, S., Iampornsin, T., et al. (2012). A novel assay detecting recall response to Mycobacterium tuberculosis: comparison with existing assays. Tuberculosis (Edinb) 92, 321-327. doi: 10.1016/j.tube.2012.03.008

Http://Www.Ohri.Ca/Programs/Clinical_Epidemiology/Oxford.Asp.

Huang, A. J., and Nunez, M. (2015). Outcomes in HIV/HBV-coinfected patients in the tenofovir era are greatly affected by immune suppression. J. Int. Assoc. Provid. AIDS Care 14, 360-368. doi: 10.1177/2325957415586258

Jaroszewicz, J., Reiberger, T., Meyer-Olson, D., Mauss, S., Vogel, M., Ingiliz, P., et al. (2012). Hepatitis B surface antigen concentrations in patients with $\mathrm{HIV} / \mathrm{HBV}$ co-infection. PLoS One 7, e43143. doi: 10.1371/journal.pone.0043143

Kitrinos, K. M., Corsa, A., Liu, Y., Flaherty, J., Snow-Lampart, A., Marcellin, P., et al. (2014). No detectable resistance to tenofovir disoproxil fumarate after 6 years of therapy in patients with chronic hepatitis B. Hepatology 59, 434-442. doi: 10.1002/hep.26686

Kosi, L., Reiberger, T., Payer, B. A., Grabmeier-Pfistershammer, K., Strassl, R., Rieger, A., et al. (2012). Five-year on-treatment efficacy of lamivudine-, tenofovirand tenofovir + emtricitabine-based HAART in HBV-HIV-coinfected patients. J. Viral. Hepat. 19, 801-810. doi: 10.1111/j.1365-2893.2012.01601.x

Li, Y., Xie, J., Han, Y., Wang, H., Zhu, T., Wang, N., et al. (2016). Lamivudine monotherapy-based cART is efficacious for $\mathrm{HBV}$ treatment in $\mathrm{HIV} / \mathrm{HBV}$ coinfection when baseline HBV DNA <20,000 IU/mL. J. Acquir. Immune Defic. Syndr 72, 39-45. doi: 10.1097/QAI.0000000000000927

Lucifora, J., and Protzer, U. (2016). Attacking hepatitis B virus cccDNA-the holy grail to hepatitis B cure. J. Hepatol. 64, S41-S48. doi: 10.1016/j.jhep.2016.02.009

Luo, A., Jiang, X., and Ren, H. (2018). Lamivudine plus tenofovir combination therapy versus lamivudine monotherapy for HBV/HIV coinfection: a metaanalysis. Virol. J. 15, 139. doi: 10.1186/s12985-018-1050-3

Martin-Carbonero, L., Teixeira, T., Poveda, E., Plaza, Z., Vispo, E., Gonzalez-Lahoz, J., et al. (2011). Clinical and virological outcomes in HIV-infected patients with chronic hepatitis B on long-term nucleos(t)ide analogues. AIDS 25, 73-79. doi: 10.1097/QAD.0b013e328340fde2

Matthews, G. V., Ali, R. J., Avihingsanon, A., Amin, J., Hammond, R., Bowden, S., et al. (2013). Quantitative HBsAg and HBeAg predict hepatitis B seroconversion after initiation of HAART in HIV-HBV coinfected individuals. PLoS One 8, e61297. doi: 10.1371/journal.pone.0061297

Matthews, G. V., Avihingsanon, A., Lewin, S. R., Amin, J., Rerknimitr, R., Petcharapirat, P., et al. (2008). A randomized trial of combination hepatitis B therapy in HIV/HBV coinfected antiretroviral naive individuals in Thailand. Hepatology 48, 1062-1069. doi: 10.1002/hep.22462

Maylin, S., Boyd, A., Lavocat, F., Gozlan, J., Lascoux-Combe, C., Miailhes, P., et al. (2012). Kinetics of hepatitis B surface and envelope antigen and prediction of treatment response to tenofovir in antiretroviral-experienced HIV-hepatitis B virus-infected patients. AIDS 26, 939-949. doi: 10.1097/ QAD.0b013e328352224d

Miailhes, P., Trabaud, M. A., Pradat, P., Lebouche, B., Chevallier, M., Chevallier, P., et al. (2007). Impact of highly active antiretroviral therapy (HAART) on the 
natural history of hepatitis B virus (HBV) and HIV coinfection: relationship between prolonged efficacy of HAART and HBV surface and early antigen seroconversion. Clin. Infect. Dis. 45, 624-632. doi: 10.1086/520752

Moher,D., Liberati, A., Tetzlaff, J., and Altman, D. G. (2009a). Preferred reporting items for systematic reviews and meta-analyses: the PRISMA statement. Ann. Intern. Med. 151, 264-269, W264. doi: 10.7326/0003-4819-151-4-200908180-00135

Moher, D., Liberati, A., Tetzlaff, J., and Altman, D. G. (2009b). Preferred reporting items for systematic reviews and meta-analyses: the PRISMA statement. PLoS Med. 6, e1000097. doi: 10.1371/journal.pmed.1000097

Moher, D., Liberati, A., Tetzlaff, J., and Altman, D. G. (2009c). Preferred reporting items for systematic reviews and meta-analyses: the PRISMA statement. BMJ 339, b2535. doi: 10.1136/bmj.b2535

Moseley, A. M., Herbert, R. D., Sherrington, C., and Maher, C. G. (2002). Evidence for physiotherapy practice: a survey of the Physiotherapy Evidence Database (PEDro). Aust. J. Physiother. 48, 43-49. doi: 10.1016/S0004-9514(14)60281-6

Nuesch, R., Ananworanich, J., Srasuebkul, P., Chetchotisakd, P., Prasithsirikul, W., Klinbuayam, W., et al. (2008). Interruptions of tenofovir/emtricitabine-based antiretroviral therapy in patients with HIV/hepatitis B virus co-infection. AIDS 22, 152-154. doi: 10.1097/QAD.0b013e3282f303bf

Nunez, M., Perez-Olmeda, M., Diaz, B., Rios, P., Gonzalez-Lahoz, J., and Soriano, V. (2002). Activity of tenofovir on hepatitis B virus replication in HIV-co-infected patients failing or partially responding to lamivudine. AIDS 16, 2352-2354. doi: 10.1097/00002030-200211220-00023

Peters, M. G., Andersen, J., Lynch, P., Liu, T., Alston-Smith, B., Brosgart, C. L., et al. (2006). Randomized controlled study of tenofovir and adefovir in chronic hepatitis B virus and HIV infection: ACTG A5127. Hepatology 44, 1110-1116. doi: 10.1002/hep.21388

Price, H., Dunn, D., Pillay, D., Bani-Sadr, F., De Vries-Sluijs, T., Jain, M. K., et al. (2013). Suppression of HBV by tenofovir in HBV/HIV coinfected patients: a systematic review and meta-analysis. PLoS One 8, e68152. doi: 10.1371/ journal.pone.0068152

Price, H., Dunn, D., Zachary, T., Vudriko, T., Chirara, M., Kityo, C., et al. (2017). Hepatitis B serological markers and plasma DNA concentrations. AIDS 31, 1109-1117. doi: 10.1097/QAD.0000000000001454

Ristig, M. B., Crippin, J., Aberg, J. A., Powderly, W. G., Lisker-Melman, M., Kessels, L., et al. (2002). Tenofovir disoproxil fumarate therapy for chronic hepatitis B in human immunodeficiency virus/hepatitis B virus-coinfected individuals for whom interferon-alpha and lamivudine therapy have failed. J. Infect. Dis. 186, 1844-1847. doi: 10.1086/345770

Rosenthal, R. (1979). The file drawer problem and tolerance for null results. Psychological Bulletin 86, 638-641. doi: 10.1037/0033-2909.86.3.638

Stephan, C., Berger, A., Carlebach, A., Lutz, T., Bickel, M., Klauke, S., et al. (2005). Impact of tenofovir-containing antiretroviral therapy on chronic hepatitis B in a cohort co-infected with human immunodeficiency virus. J. Antimicrob. Chemother. 56, 1087-1093. doi: 10.1093/jac/dki396

Stuck, A. E., Rubenstein, L. Z., and Wieland, D. (1998). Bias in meta-analysis detected by a simple, graphical test. Asymmetry detected in funnel plot was probably due to true heterogeneity. $B M J 316,469$. author reply $470-461$. doi: 10.1136/bmj.316.7129.469
Tan, L. K., Gilleece, Y., Mandalia, S., Murungi, A., Grover, D., Fisher, M., et al. (2009). Reduced glomerular filtration rate but sustained virologic response in HIV/hepatitis B co-infected individuals on long-term tenofovir. J. Viral. Hepat. 16, 471-478. doi: 10.1111/j.1365-2893.2009.01084.x

Thio, C. L., and Locarnini, S. (2007). Treatment of HIV/HBV coinfection: clinical and virologic issues. AIDS Rev 9, 40-53. doi: 10.1089/aid.2007.9999

Tseng, T. C., Liu, C. J., Yang, H. C., Su, T. H., Wang, C. C., Chen, C. L., et al. (2012). High levels of hepatitis B surface antigen increase risk of hepatocellular carcinoma in patients with low HBV load. Gastroenterology 142, 1140-1149 e1143. doi: 10.1053 /j.gastro.2012.02.007

Unaids (2018). Global HIV \& AIDS statistics-2018 fact sheet. WORLD AIDS DAY 2018.

Van Griensven, J., Phirum, L., Choun, K., Thai, S., De Weggheleire, A., and Lynen, L. (2014). Hepatitis B and C co-infection among HIV-infected adults while on antiretroviral treatment: long-term survival, CD4 cell count recovery and antiretroviral toxicity in Cambodia. PLoS One 9, e88552. doi: 10.1371/ journal.pone.0088552

Vinikoor, M. J., Sinkala, E., Chilengi, R., Mulenga, L. B., Chi, B. H., Zyambo, Z., et al. (2017). Impact of antiretroviral therapy on liver fibrosis among human immunodeficiency virus-infected adults with and without HBV coinfection in Zambia. Clin. Infect. Dis. 64, 1343-1349. doi: 10.1093/cid/cix122

Wu, Y. S., Zhang, W. W., Ling, X. M., Yang, L., Huang, S. B., Wang, X. C., et al. (2016). Efficacy and safety of tenofovir and lamivudine in combination with efavirenz in patients co-infected with human immunodeficiency virus and hepatitis B virus in China. Chin. Med. J. (Engl) 129, 304-308. doi: 10.4103/03666999.174509

Yang, Y., Gao, J., Li, H. L., Zheng, W., Yang, G., Zhang, W., et al. (2016). Doseresponse association between hepatitis B surface antigen levels and liver cancer risk in Chinese men and women. Int J Cancer 139, 355-362. doi: 10.1002/ ijc.30086

Zeisel, M. B., Lucifora, J., Mason, W. S., Sureau, C., Beck, J., Levrero, M., et al. (2015). Towards an HBV cure: state-of-the-art and unresolved questionsreport of the ANRS workshop on HBV cure. Gut 64, 1314-1326. doi: 10.1136/ gutjnl-2014-308943

Zoutendijk, R., Zaaijer, H. L., De Vries-Sluijs, T. E., Reijnders, J. G., Mulder, J. W., Kroon, F. P., et al. (2012). Hepatitis B surface antigen declines and clearance during long-term tenofovir therapy in patients coinfected with HBV and HIV. J. Infect. Dis. 206, 974-980. doi: 10.1093/infdis/jis439

Conflict of Interest Statement: The authors declare that the research was conducted in the absence of any commercial or financial relationships that could be construed as a potential conflict of interest.

Copyright (c) 2019 Jiang, Su, Song, Zhu, Xia, Dai, Wang, Zhang and Wu. This is an openaccess article distributed under the terms of the Creative Commons Attribution License (CC BY). The use, distribution or reproduction in other forums is permitted, provided the original author(s) and the copyright owner(s) are credited and that the original publication in this journal is cited, in accordance with accepted academic practice. No use, distribution or reproduction is permitted which does not comply with these terms. 